\title{
AN EXTREMAL PROBLEM FOR POLYNOMIALS WITH A PRESCRIBED ZERO
}

\author{
IGOR Ž. MILOVANOVIĆ
}

ABSTRACT. In this paper a new elementary proof for solving one extremal problem of real polynomials with a given real zero is given.

Let $b \geqslant 0$ and let $R_{n}^{b}$ be a set of all polynomials $P(Z)=a_{0}+\cdots+a_{n} Z^{n}$, $Z=e^{i q}$, where $a_{0}, \ldots, a_{n}$ are real coefficients, that satisfy $P(b)=0$. For a given polynomial $P(Z) \in R_{n}^{b}$ let us introduce

$$
\|P\|_{c}^{2}=\frac{1}{2 \pi} \int_{0}^{2 \pi}|P(Z)|^{2} d q, \quad\|P\|_{L}^{2}=\frac{1}{2 \pi} \int_{0}^{2 \pi}\left|\frac{P(Z)}{Z-b}\right|^{2} d q .
$$

In [1] (see also [2]) the following extremal problem is solved:

$$
\min \frac{\|P\|_{c}^{2}}{\|P\|_{L}^{2}}=1+b^{2}-2 b \cos \frac{\pi}{n+1}, \quad P \in R_{n}^{b} .
$$

In this paper, using the original procedure, besides the problem (1), we solved the complementary problem:

$$
\max \frac{\|P\|_{c}^{2}}{\|P\|_{L}^{2}}=1+b^{2}+2 b \cos \frac{\pi}{n+1}, \quad P \in R_{n}^{b} .
$$

Proposition. For each polynomial $P(Z)$ from the set $R_{n}^{b}$, (1) and (2) hold. The required minimum (maximum) in $(1)((2))$ is achieved for

$$
P(Z)=(Z-b) \sum_{k=1}^{n} C_{k} Z^{k-1} \sin \frac{k \pi}{n+1}, \quad Z=e^{i q},
$$

where $C_{k}=C\left(C_{k}=(-1)^{k-1} C\right), k=1, \ldots, n, C=$ const $\neq 0$.

Proof. Since $P(Z)$ belongs to the set $R_{n}^{b}$ we can write it in the form

$$
P(Z)=(Z-b)\left(x_{1}+x_{2} Z+\cdots+x_{n} Z^{n-1}\right), \quad Z=e^{i q},
$$

where $x_{1}, \ldots, x_{n}$ are real numbers. Now we have

$$
\|P\|_{L}^{2}=\sum_{k=1}^{n} x_{k}^{2}
$$

Received by the editors December 18, 1984.

1980 Mathematics Subject Classification. Primary 26D05, 26D10.

C1986 American Mathematical Society $0002-9939 / 86 \$ 1.00+\$ .25$ per page 
and

$$
\|P\|_{c}^{2}=\left(1+b^{2}\right) \sum_{k=1}^{n} x_{k}^{2}-2 b \sum_{k=1}^{n-1} x_{k} x_{k+1} .
$$

In [3], as a special case of a general inequality, the following double inequality is proved:

$$
-\cos \frac{\pi}{n+1} \sum_{k=1}^{n} x_{k}^{2} \leqslant \sum_{k=1}^{n-1} x_{k} x_{k+1} \leqslant \cos \frac{\pi}{n+1} \sum_{k=1}^{n} x_{k}^{2} .
$$

Equality holds in the left-hand inequality if and only if

$$
x_{k}=C \sin \frac{k \pi}{n+1}, \quad k=1, \ldots, n,
$$

where $C=$ const $\neq 0$, and in the right-hand inequality if and only if

$$
x_{k}=(-1)^{k-1} C \sin \frac{k \pi}{n+1}, \quad k=1, \ldots, n,
$$

where $C=$ const $\neq 0$. (On the inequality (5) see also [4-7].) From (3), (4) and (5) we obtain

$$
\begin{aligned}
\|P\|_{c}^{2} & =\left(1+b^{2}\right)\|P\|_{L}^{2}-2 b \sum_{k=1}^{n-1} x_{k} x_{k+1} \\
& \leqslant\left(1+b^{2}\right)\|P\|_{L}^{2}+2 b \cos \frac{\pi}{n+1}\|P\|_{L}^{2},
\end{aligned}
$$

where from (2) follows. In the same way from (3), (4) and (5) we obtain the solution of the problem (1). From equality in (5) we obtain polynomials for which the extremum in (1) and (2) is obtained.

\section{REFERENCES}

1. J. D. Donaldson and Q. I. Rahman, Inequalities for polynomials with a prescribed zero, Pacific J. Math. 41 (1972), 375-378.

2. A. Aziz, Inequalities for polynomials with a prescribed zero, Canad. J. Math. 34 (1982), 737-740.

3. G. V. Milovanović and I. Ž. Milovanović, Some discrete inequalities of Opial's type, Acta Sci. Math. 47 (1984), 413-417.

4. V. M. Tihomirov, Some problems of approximation theory, Univ. of Moscow, 1976. (Russian)

5. L. Fejer, Über trigonometrische Polynome Gesammelte Arbeiten, Band 1, Akad. Kiadó, Budapest. 1970, pp. 842-872.

6. G. Pólya and G. Szegő, Aufgaben und Lehrsätze aus der Analysis, Springer, Berlin and New York, 1964.

7. A. G. Babenko, An extremal problem for polynomials, Mat. Zametki 35 (1984), 349-356. (Russian)

Faculty of Electronic Engineering, University of Nis, Beogradska 14, P. O. Box 73, 18000 Nis, Yugoslavia 